\title{
A fratura da alteridade em "Amor", de Clarice Lispector, e Um crime delicado, de Sérgio Sant'Anna
}

Valter Henrique de Castro Fritsch ${ }^{1}$

É por meio do imaginário simbólico que conferimos conexão e sentido à realidade fragmentada da nossa existência, pondo em comunicação nosso mundo i-religado com as religações de um sentido de implicação.

Castoriadis

Existe uma inesgotável capacidade criadora na imaginação humana. Ela é a responsável pela potencialização das dimensões simbólicas de qualquer criação, seja ela artística ou não. Antes de criarmos algo, antes de compreendermos um conceito racionalmente, passamos pelo crivo da imaginação. Ela é a força primeva que abre toda e qualquer possibilidade para o que convencionamos chamar de realidade e, mesmo assim, apresenta-se como sua força opositora. A imaginação é geralmente associada ao irreal, à inverdade, ao mito, ao sonho e ao devaneio, enquanto a realidade é aquela que sustenta as bases do axioma filosófico da busca da verdade ou das verdades do pensamento ocidental.

Contudo, o pensamento filosófico surge, sustenta-se e é atravessado pela imaginação e pela dimensão subjetiva de seus produtos - os sonhos, os devaneios, as histórias, a literatura, as artes, a religião e a mitologia. Os produtos da imaginação, ao oporem-se àqueles da realidade, criam uma espécie de cisão - uma fratura - entre as dimensões do pensamento simbólico, que encontra suas raízes na filosofia de Platão, e as do raciocínio lógico-aristotélico. A fratura humana nasce a partir de nossa necessidade hermenêutica de dar sentido às coisas e aos acontecimentos do mundo que nos cerca e a partir de nossa interação com as alteridades.

O presente trabalho é um esforço interpretativo para lançar luzes sobre a questão da condição da fratura humana em sua busca hermenêutica de dar sentido ao mundo que a cerca através da compreensão da alteridade em duas obras literárias contemporâneas: "Amor" (1960) de Clarice Lispector e Um Crime Delicado (1997) de Sérgio Sant'Anna. A partir da

\footnotetext{
${ }^{1}$ Doutor em literaturas de língua inglesa e professor da Universidade Federal do Rio Grande (FURG), Rio Grande, RS, Brasil. (Dorcid.org/0000-0001-7787-1945. E-mail: valter.fritsch@yahoo.com.br
} 
leitura e aproximação das duas obras e da jornada de seus protagonistas, busco analisar e compreender a fratura da alteridade a partir do contato das personagens Ana e Antônio Martins com pessoas com uma deficiência física - um homem cego e uma mulher manca, respectivamente - e como esse encontro com a alteridade da falta os modifica sobremaneira. Para tanto, necessário se faz discutir primeiro o conceito de fratura - como é compreendido no presente artigo.

Nascemos incompletos. Do momento de nossa chegada ao mundo até o dia de nossa morte aprendemos, através da linguagem, a dar sentido às coisas do mundo e a nossa própria existência. No entanto, toda e qualquer construção de sentido é atravessada pela imaginação e é, portanto, uma construção simbólica fadada ao fracasso, pois toda definição de algo ou de um conceito é uma espécie de claustro, uma prisão de imagens e palavras agrupadas que buscam significar cada experiência do indivíduo imerso na coletividade do seu meio social. Como estamos implicados racional, subjetiva e imageticamente em nossos conceitos, toda definição nasce fraturada, pois que é a construção de um sujeito que se constituiu na própria fratura. Castor Bartolomé Ruiz (2003, p. 54) apresenta uma reflexão bastante elucidativa sobre o tema em seu livro Os paradoxos do imaginário:

A pessoa não é um produto acabado, mas uma criatura aberta pela ambiguidade e enriquecida pelo desejo. Não constituímos um ser definido, mas perambulamos entre a necessidade de plenitude e a busca de sentido. Não habitamos um mundo natural, mas vivemos numa selva de símbolos. Não somos um animal meramente racional, mas criaturas hermenêuticas que dotam de significado tudo o que tocam. Não nos adaptamos funcionalmente à realidade, mas a transformamos por meio da práxis criadora. Não respondemos compulsivamente a pulsões definidas pela nossa natureza, mas construímos nosso modo de ser a partir do desejo permanente; desejo que não está definido em nós, mas que nos define pela abertura sobre o que desejar e por que desejar isso e não aquilo. Não nos sujeitamos funcionalmente ao meio ambiente, mas construímos sujeitos e sociedade por meio da práxis, pois somos seres práxicos. Não ficamos num presente, senão que nos transcendemos ansiosamente para um futuro sempre em aberto. A tensão é a categoria que interaciona e implica conflitivamente as dimensões divergentes e até contraditórias da personalidade 
humana. Somos uma criatura fraturada pelo conflito e rejuntada pela tensão existencial. Estamos impregnados pelo paradoxal. Esta é a realidade em que estamos imersos e a partir da qual, sem poder emergir para uma hipotética distância racional, objetiva ou neutra, pretendemos desenhar alguns traços de nossa própria identidade.

Tendo em vista tais conceitos, fica claro que a fratura nasce justamente da incompletude do sujeito diante do mundo. Não há unidade, mas, sim, um conglomerado de características que só ficam claras para o sujeito quando em contato com as alteridades do mundo. O sujeito estabelece quem é a partir da visão do outro e do diferente - eu sou o que o outro não é e me constituo a partir desta alteridade. E, se somos criaturas fraturadas, como sugere Ruiz, o somos pela e através da alteridade. Tal consciência parece clara na mitologia, pois em muitos mitos fundadores, a tomada de consciência sobre o outro é o início da jornada para a queda e para o conhecimento. No mito bíblico do Jardim do Éden, a árvore do conhecimento do bem e do mal pode ser vista como uma metáfora para a tomada de consciência do outro - o homem não mais como uma parte do todo, mas diferente do todo e um agente criador que modifica o mundo que habita.

No conto "Amor", de Clarice Lispector, a personagem Ana vive uma vida bastante tranquila dentro de uma rotina que organiza sua existência. Ana está imersa em uma espécie de sono do cotidiano - uma realidade que constitui sua experiência de vida a partir de suas tarefas e de seus papéis de mãe, dona de casa e esposa.

Os filhos de Ana eram bons, uma coisa verdadeira e sumarenta. Cresciam, tomavam banho, exigiam para si, malcriados, instantes cada vez mais completos. A cozinha era enfim espaçosa, o fogão enguiçado dava estouros. O calor era forte no apartamento que estavam aos poucos pagando. Mas o vento batendo nas cortinas que ela mesma cortara lembrava-lhe que se quisesse podia parar e enxugar a testa, olhando o calmo horizonte. Como um lavrador. Ela plantava as sementes que tinha na mão, não outras, mas essas apenas. E cresciam árvores. Crescia sua rápida conversa com o cobrador de luz, crescia a água enchendo o tanque, cresciam seus filhos, crescia a mesa com comidas, o marido chegando com os jornais e sorrindo de fome, o canto importuno das empregadas do edifício. Ana dava a tudo, tranquilamente, sua mão pequena e forte, sua corrente de vida (Lispector, 2009, p. 19). 
A personagem observa tudo ao seu entorno crescer e desenvolver-se dentro da rotina que organiza a sua vida. Crescem árvores, filhos, conversas, volume de água no tanque, enfim, tudo ao redor de Ana parece desenvolver-se e atingir uma adequada plenitude, o que parece dar a ela certa tranquilidade para viver sua vida, como se infere da última frase da citação. Os desejos mais subjetivos da personagem foram acomodados, como o narrador sugere: "todo o seu desejo vagamente artístico encaminhara-se a muito no sentido de tornar os dias realizados e belos". E sua necessidade de interferir no mundo parece condicionada à organização e a sua tentativa de harmonizar ambientes: "Parecia ter descoberto que tudo era passível de aperfeiçoamento, a cada coisa emprestaria uma aparência harmoniosa; a vida podia ser feita pela mão do homem" (Lispector, 2009, p. 20).

É no encontro apaziguado de seus desejos e de seu cotidiano que a personagem Ana vai tecendo sua identidade. Por meio das imagens que permeiam seu mundo, Ana vai atribuindo significados de um modo criativo, ainda que quase passivo, diante do tecido imagético que se apresenta a ela diariamente. Suas funções como mãe, dona de casa e esposa ocupam seus pensamentos e organizam o seu modus operandi. No entanto, a imaginação, antes mesmo da racionalidade, é que será responsável por uma cisão - uma fratura - na rotina de Ana. Ao encontrar um homem cego mascando chicletes na parada do bonde que a levaria para casa, a protagonista do conto de Lispector é despertada de seu "sono" do cotidiano.

Foi então que olhou para o homem parado no ponto. A diferença entre ele e os outros é que ele estava realmente parado. De pé, suas mãos se mantinham avançadas. Era um cego. O que havia mais que fizesse Ana se aprumar em desconfiança? Alguma coisa intranquila estava sucedendo. Então ela viu: o cego mascava chicles... Um homem cego mascava chicles (Lispector, 2009, p. 21).

Antes da racionalidade consciente, Ana é atravessada por sensações. Por meio de uma imagem significativa - o homem cego mascando chicletes - a personagem entra em uma espécie de torpor catártico ${ }^{2}$ que

\footnotetext{
${ }^{2}$ Há ainda a possibilidade de interpretar esse torpor a partir do conceito de quiasmo, ou seja, um objeto cuja disposição é cruzada produzindo um novo sentido. Existem já alguns estudos que apresentam o conceito de quiasmo na obra de Lispector, tais como Franco Júnior, que aponta que o quiasmo ocorre quando "uma imagem é a predominante, e é o simulacro da outra, o seu reflexo invertido. Uma subverte a outra" (Franco Júnior, 2002, p. 141); e Alonso que afirma que "o
} 
vai conduzi-la para uma jornada para o seu interior. Ruiz nos lembra que as reações do imaginário dificilmente podem ser detalhadas no momento de sua criação e devem, portanto, ser descritas através de seus efeitos, pois nunca poderão ser explicadas e descritas de maneira conclusiva (Ruiz, 2003, p. 30). No caso de Ana, o encontro com o cego a leva para um novo momento de sua existência - o momento da percepção da fratura através da alteridade da deficiência.

O choque da personagem não é descrito pelo narrador de uma forma racionalizada. Há muito pouco de racionalização sobre o que está acontecendo com Ana. Ela foi arrebatada pela imagem do homem cego pela fragilidade do homem em sua deficiência e, ainda assim, entretido em seu ato de mastigação. Ana perde-se da realidade e adentra a sua psique através do devaneio e da imaginação. $\mathrm{O}$ chão parece dissolver-se debaixo de seus pés, e a personagem, que não consegue parar de olhar para o cego, já não tem mais certeza de onde está, até o momento em que uma freada brusca do bonde a desperta para um estado de semiconsciência, fazendo-a gritar e derrubar a sacola com ovos que trazia no colo. Contudo, mesmo desperta para o ato de apanhar a sacola e os ovos quebrados, Ana percebe que o mundo não pode voltar a ser o que era.

A rede perdera o sentido e estar no bonde era um fio partido; não sabia o que fazer com as compras no colo. E como uma estranha música, o mundo recomeçava ao seu redor. $\mathrm{O}$ mal estava feito. Por quê? Teria esquecido de que havia cegos? A piedade a sufocava. Ana respirava pesadamente. Mesmo as coisas que existiam antes do acontecimento estavam agora de sobreaviso, tinham um ar mais hostil, perecível... O mundo se tornara de novo um mal-estar. Vários anos ruíam, as gemas amarelas escorriam. Expulsa de seus próprios dias, parecia-lhe que as pessoas na rua eram periclitantes, que se mantinham por um mínimo equilíbrio à tona da escuridão - e por um momento a falta de sentido deixava-as tão livres que elas não sabiam para onde ir. Perceber uma ausência de lei foi tão súbito que Ana se agarrou ao banco da frente, como se pudesse cair do bonde, como se as coisas pudessem ser revertidas com a mesma calma com o que não eram (Lispector, 2009, p. 23).

narrador clariciano lança mão da dimensão especular do quiasmo, ou seja, uma espécie de $\mathrm{X}$ em que se fixam dois contrários relacionados numa mesma experiência” (Alonso, 2013, p. 9). 
Como dito pelo narrador, Ana percebe uma ausência de lei no mundo e, por alguns instantes, sente-se em suspenso, a ponto de segurar-se no banco da frente, como se pudesse cair se não o fizesse. A rede de significados que a personagem havia tecido para o seu mundo até então é confrontada pela deficiência do homem, que, diferentemente do cenário cotidiano de Ana, não atingira sua plenitude. A alteridade da falta, aqui representada pela ausência do sentido da visão, coloca a personagem em uma dimensão distinta da em que se encontrava até então, obrigando-a a confrontar sua própria visão de mundo e de si mesma. O interessante é que o confronto se apresenta à Ana não pelo crivo da razão aristotélica, mas, sim, pelo arrebatamento simbólico platônico. A imagem da deficiência a atravessa e, a partir desse encontro, a personagem não é mais capaz de enxergar o mundo e as pessoas como antes. Na percepção da alteridade da falta, ela percebe a sua incompletude e entrega-se às suas próprias ausências. No confronto com essa alteridade, Ana entra em conflito com sua identidade e seu lugar no mundo - mundo este que a personagem agora sente sem leis que possam assegurar o seu bem-estar e o dos seus entes queridos.

Acometida por uma espécie de transe, a personagem percebe que o cotidiano que a cercava havia sido modificado. Apesar de as pessoas e as ações serem as mesmas, nada mais seria como antes.

Ela apaziguara tão bem a vida, cuidara tanto para que esta não explodisse. Mantinha tudo em serena compreensão, separava uma pessoa das outras e podia-se escolher pelo jornal o filme da noite - tudo feito de um modo que um dia se seguisse ao outro. E um cego mascando goma despedaçava tudo isso. E através da piedade aparecia a Ana uma vida cheia de náusea doce, até a boca (Lispector, 2009, p. 23).

Após perceber que havia passado de seu ponto, Ana salta do bonde e decide entrar no Jardim Botânico, onde senta em um banco e contempla o nada. Ela tem a sensação de ter "saltado no meio da noite" (Lispector, 2009, p. 24). A personagem está perdida dentro de si, buscando uma nova constituição que ressignifique sua identidade, que se encontra dilacerada. O encontro com a deficiência - com a falta e fragilidade do outro - constitui a possibilidade da criação de uma nova existência para Ana. O choque com a alteridade, provoca a fratura e lança a personagem em um espaço vazio, representado pelo Jardim 
Botânico, que pode alçar simbolicamente outras interpretações. Como Jean Chevalier e Alan Cheerbrant bem lembram em seu Dicionário de símbolos, o jardim pode ser "uma alegoria do paraíso e é o espaço tradicionalmente destinado à representação de estados espirituais e da volta para o infinito" (Chevalier e Cheerbrant, 2015, p. 51). Ana dá uma espécie de salto metafísico depois de seu encontro com o homem cego, entrando em um estado de contemplação de quem realmente é e de percepção da fragilidade da vida que leva e das pessoas com quem coabita. A percepção desta fragilidade nasce da fratura - provocada pelo encontro com a falta, a ausência e a deficiência representadas pelo homem cego. O salto metafísico de Ana tem raízes mitológicas, já que a personagem, a exemplo de outras figuras míticas, está sendo guiada em sua jornada por um cego - impossível não relacionar a importância das Parcas e de Tirésias na mitologia greco-romana em seus papeis de guias de heróis em suas jornadas e aventuras. Mas, ao contrário dos heróis mitológicos, Ana fará sua jornada dentro de si mesma - uma compreensão de si, através do outro, como sugere Ruiz.

A alteridade é a referência primeira e concomitante a constituição da própria identidade. $\mathrm{O}$ outro não é alguém posterior à configuração da pessoa, senão que constitui a condição de possibilidade para sua existência. A alteridade aparece como um paradoxo que estabelece um distanciamento racional, une e separa o sujeito do objeto. A alteridade não é uma opção do ser humano, mas uma condição de possibilidade para existir como pessoa (Ruiz, 2003, p. 56).

É desse mesmo encontro com a alteridade da deficiência que a vida de Antônio Martins, personagem protagonista e narrador da obra Um crime delicado, de Sérgio Sant'Anna, é modificada. O romance de Sant'Anna, escrito em 1997, alçou sucesso rapidamente e deu a seu autor o prêmio Jabuti - prêmio este que já havia vencido duas outras vezes com os romances O concerto de João Gilberto no Rio de Janeiro (1987) e Amazona (1986). Ambientado no Rio de Janeiro, o romance Um crime delicado narra a trajetória de Antônio Martins, um crítico de teatro por volta de seus 50 anos que se apaixona por Inês, uma misteriosa jovem que ele conhece em um café e pela qual desenvolve um fascínio obsessivo, dando especial atenção ao fato de a moça ser manca.

A importância da deficiência de Inês fica clara desde as primeiras páginas do romance, quando Antônio descreve a mulher que vê sentada em um café dando atenção a seu rosto, seus seios e seu cabelo. Contudo, 
Inês está sentada e, portanto, sua deficiência não pode ser percebida por Antônio em um primeiro momento. No entanto, o próprio personagem assume que algo o fascinava para além do que podia ver.

Então, seria um exagero dizer que eu me sentira atraído desde o princípio por aquilo, como os acontecimentos posteriores poderiam sugerir. A menos que se especule com a ideia de que no primeiro olhar já está contido o tudo, o conhecimento que uma pessoa apenas confirmará da outra e o destino que viverão em comum (Sant'Anna, 1997, p. 9).

Um fato interessante a ser observado é que, na primeira vez que Antônio vê Inês no café, ele percebe que as paredes do estabelecimento são espelhadas e que, através dos espelhos, ele pode observar e ser observado pela moça em diferentes ângulos e perspectivas. Nesse caso, a realidade apresentada a Antônio é multifacetada e pode ser preenchida pela sua imaginação - exercício que ele faz com certa proficiência levando em conta seu ofício de crítico teatral. Como no caso do jardim, em que a personagem Ana de Lispector se encontra, que foi alçado ao patamar de símbolo, a sala de espelhos também pode ter uma representação para além da simples descrição do espaço geográfico. A imaginação simbólica pode atribuir diferentes significados a uma imagem banal, e a literatura é um campo profícuo para que isso ocorra. De acordo com Gilbert Durand,

Há casos em que o signo é forçado a perder a sua arbitrariedade teórica: quando remete a abstrações, especialmente qualidades espirituais ou morais dificilmente apresentáveis em carne e osso. Para designar a justiça ou a verdade, o pensamento não pode se entregar ao arbitrário, pois esses conceitos não são tão evidentes como os que repousam em percepções objetivas. É necessário então recorrer-se a uma modalidade de signos complexos. Chegamos a imaginação simbólica, quando o significado não é mais absolutamente apresentável e o signo só pode referir-se a um sentido, não há um objeto sensível (Durand, 1988, p. 15).

As representações simbólicas sobre o espelho são muitas e vão desde atribuições divinatórias até a percepção da feminilidade na mitologia e dos astros e estrelas. Contudo, voltando a Chevalier e Cheerbrant, vemos que o espelho "reflete a verdade, a sinceridade, o conteúdo do coração e da consciência." (Chevalier e Cheerbrant, 2015, p. 393). Então, 
fico tentado a afirmar que, mesmo que não tenha percebido racionalmente e de imediato a deficiência de Inês, que será tão cara a Antônio no desenrolar do romance, essa fora percebida desde o primeiro momento, através de sua percepção intuitiva, inconsciente e subjetiva do jogo de espelhos que aqui se apresenta como um símbolo do desnudamento das personalidades das personagens que, ao se conhecerem, enxergam-se por completo. Antônio confirma esta possibilidade conforme avança em sua narrativa: "Pois os espelhos que nos ligavam, inclusive na ausência, refletiam, para além dos corpos para além, até, daquilo meio secreto em seu corpo - uma imagem, digamos, do espírito" (Sant'Anna, 1997, p. 32).

Ao contrário de Ana, Antônio é seguro de si e de suas capacidades intelectuais e de percepção da realidade. Como exigência de seu ofício crítico de teatro -, ele deve observar a tudo com um detalhamento minucioso para que possa estabelecer reflexões sobre aquilo que assiste e percebe. Em sua narrativa, Antônio usa termos que remetem ao teatro e ao palco com certa insistência. As palavras cena, palco, figurino, cenário, peça e personagem são usadas diversas vezes em sua narrativa, como se ao contar a sua vida estivesse descrevendo a trajetória de uma peça teatral, enquanto analisa criticamente cada um dos fatos narrados.

Ainda diferentemente de Ana, que se encontrava distraída ao perceber o homem cego, Antônio tem uma espécie de premonição de que algo muito importante aconteceria no dia em que encontra Inês e conscientiza-se de sua deficiência.

E se não fosse tão lento, não teria sido forçado a dar uma olhada indiscreta para as pernas daquela jovem mulher, em sua calça jeans - que ela usava com uma camisa listrada, de mangas compridas, o que lhe dava ao mesmo tempo um toque de simplicidade e distinção - para perceber que uma delas era um tanto rija e atrofiada (Sant'Anna, 1997, p. 15).

Ao tomar conhecimento da deficiência de Inês, a moça não sai mais da cabeça de Antônio e passa a habitar seus pensamentos de forma obsessiva. No entanto, Antônio resiste em assumir, mesmo para si mesmo, que a deficiência de Inês lhe encanta. Há, inclusive, uma resistência de mencionar a deficiência de Inês e, uma vez rompida essa resistência, Antônio consegue confessar que encontrou beleza em Inês.

Com suas propriedades de velar e sugerir, foi esse biombo que descortinou para mim não uma sequência de imagens encadeadas, 
mas uma cena relâmpago, como um instantâneo fotográfico iluminado pelo espoucar de um flash na escuridão: a de Inês deitada, para não dizer desfalecida, sobre um leito ou divã, enquanto eu me debruçava sobre o seu corpo. Uma cena quase subliminar em minhas recordações, mas suficientemente materializada para incluir uma perna atrofiada, contrastando com a outra sadia, forte e por que não dizer? bela (Sant'Anna, 1997, p. 25).

A narrativa de Antônio é sua tentativa de ordenar os fatos para que ele mesmo entenda se cometeu ou não um crime: o estupro de Inês. Obcecado por Inês e por sua deficiência, Antônio passa a criar situações para que possa revê-la inúmeras vezes, numa espécie de vampirização da vida da moça, que passa a ser cerceada e perseguida pelo crítico. Há no enredo um nó de bastante complexidade que envolve o artista plástico Vitório Brancatti, uma espécie de tutor de Inês, que a usa como modelo de uma de suas obras. Existe a possibilidade de que Inês e Brancatti tenham se unido em uma espécie de estratagema para expor Antônio e com isso conseguir visibilidade para a obra de Brancatti. Contudo, tal complô é visto e narrado pelo olhar de Antônio, que tenta ressignificar tudo o que viveu com Inês na tentativa de entender se a relação amorosa que teve com ela foi um estupro ou foi concedida. $\mathrm{O}$ foco deste artigo não está em desvendar o que realmente aconteceu entre Inês e Antônio, mas, sim, em entender o processo de fratura de Antônio que, ao se deparar com a deficiência de Inês, é tomado por um fascínio e passa a exercer um papel vampirizador na vida da personagem. Se, no conto de Lispector, Ana sente uma espécie de torpor seguido de náuseas ao se deparar com o cego, Antônio é tomado por um arrebatamento obsessivo com a deficiência de Inês.

Em minhas recordações eu podia figurar uma dessas pernas como uma bonita perna feminina, e a outra, o que se sabe e pode imaginar. Quanto à perna, digamos assim, lesada, não havia nela nada de repulsivo: só fazia redobrar o meu desejo de dar carinho a Inês (Sant'Anna, 1997, p. 37).

Há ainda um episódio em que Antônio machuca a perna e começa a mancar. Tomado pela ação, o personagem percebe que sente certo prazer em mancar como sua amada e começa a ter devaneios de como seria bom se ele tivesse uma bengala para auxiliá-lo em sua nova e passageira condição. Mesmo quando sua perna já está melhor, Antônio ainda enseja 
alguns passos mancando, mas desiste, pois, "aquilo que a fazia coxear já se confundia inteiramente com a pessoa dela" (Sant'Anna, 1997, p. 54).

$\mathrm{O}$ arquétipo do vampiro parece se encaixar de forma adequada ao comportamento de Antônio em relação a Inês. Em seu Dicionário de símbolos, Chevalier e Cheerbrant descrevem o vampiro como uma criatura atormentada e de apetite voraz, que sente a necessidade de sugar o sangue de suas vítimas e transferir à sua vítima essa fome devoradora - ao devorar é também devorado, pois o vampiro representaria uma inversão das forças psíquicas contra si mesmo (Chevalier e Cheerbrant, 2015, p.930). Antônio, atormentado pela imagem de Inês e arrebatado pela perna atrofiada da moça, passa a exercer o papel de vampiro, que suga as forças vitais de Inês e a deixa em uma completa ausência de sentidos. Em três encontros com Antônio, Inês chega mesmo a perder os sentidos e adormecer, ou desmaiar, na presença do homem que está cercando sua vida por todos os lados. O arquétipo do vampiro fica mais claro quando Antônio escreve uma carta para Inês falando do momento em que consumaram sexualmente a relação.

Pois, apesar do êxtase carnal e espiritual que este conhecimento me proporcionou, houve um outro ainda mais arrebatador, e deste, reconheço, você talvez fora de si não tenha percebido: provei o seu sangue, Inês, que se esvaía de um ferimento de sua orelha. Dizer que o sabor foi doce é pouco, muito pouco para expressar o que foi experimentado por mim como gosto de uma virgindade beatífica. E não haverá esse sangue estabelecido entre nós um pacto indissolúvel? (Sant'Anna, 1997, p. 110).

Antônio confessa o seu deleite em beber o sangue de Inês e, com isso, confessa também seu desejo de ter dentro de si a força, o prana, a essência vital da mulher por quem está obcecado. Se o encontro com a alteridade da deficiência provocou uma catarse existencial em Ana, Antônio é tomado por um sentimento de incompletude - é a fratura do encontro com a alteridade que se torna um momento irreversível para ambos os personagens. Antônio é atravessado pela deficiência de Inês e fica fascinado por ela, deseja ela para si a ponto de sugar o sangue de Inês. A fratura rasga o personagem internamente e desconfigura sua identidade como constituída até então, e ele passa a se enxergar como um ser incompleto e distante do contexto do qual emergiu. Antônio parece sentir quase uma necessidade de fundir-se à Inês. No entanto, é 
este o momento exato em que as personagens - Ana e Antônio - passam por um processo de epifania e reconfiguração de suas identidades.

Ao despertar do torpor e constatar que "um cego me levou ao pior de mim mesma" (Lispector, 2009, p. 27), Ana retorna para casa. Ela apresenta uma certa resistência em retomar sua vida após o encontro com o homem cego, mas, ao voltar, percebe a fragilidade do ambiente que a cerca - físico e emocional -, e chega a machucar o filho com um abraço e declara ao marido que não quer que nada lhe aconteça. Antônio, por sua vez, é julgado e absolvido, passa a habitar a obra de Brancatti em uma instalação do artista que percorre o mundo e assume o posto de crítico em um jornal de renome. Antônio fica em uma espécie de entrelugar identitário, pois já não é mais o homem que fora e não entende ainda que nova configuração é esta proposta depois de seu encontro com Inês. A necessidade das personagens de atravessarem tal ressignificação e reconfiguração identitária está diretamente ligada ao encontro com a alteridade da deficiência e a fratura que tal encontro ocasiona. De acordo com Ruiz,

O ser humano roto e fraturado, confrontado com um mundo distante e diferente de si, busca fundir-se nele, tentando expandir sua consciência sobre o mundo. Procura, desse modo, restaurar sua unidade monádica com o mundo natural, porém nunca o consegue de forma absoluta e sempre tem que se conformar com experiências relativas e fugazes de harmonia (Ruiz, 2003, p. 58).

O desejo de fundir-se com a alteridade, como apontado por Ruiz, parece ser a chave da experiência vivida por ambas as personagens. O desejo nos lança na busca da procura pela harmonia perdida - Ana e Antônio sentem que algo mudou a partir do encontro com a alteridade e a fratura provocada exigirá uma restruturação de suas próprias identidades, afetando o modo como viviam nos seus mundos até então. Esses mundos serão alargados pelo contato com a alteridade e, uma vez consumada a fratura, sua sutura só poderá ser efetuada através da produção de novos sentidos para o que haviam vivido até então. Toda construção de sentido é uma construção simbólica, que é atravessada pela imaginação e cria, através de seus produtos, possibilidades de compreensão e ressignificação a partir daquilo que foi partido. A fratura, uma vez consumada, só será sanada através desse processo de reconfiguração de sentidos pelo qual ambas as personagens terão de passar. 
A alteridade da deficiência física - fator que provoca a fratura nas personagens analisadas - é bastante significativa como uma metáfora da falta. E é na falta, na ausência de completude, que as personagens Ana e Antônio encontraram aquilo que lhes faltava também ou, ao menos, serão levados a refletir acerca desta falta. $\mathrm{O}$ desejo de fundir-se à falta nada mais é que a necessidade de mergulhar em suas próprias lacunas e suturar suas fraturas através de uma nova configuração de sentidos. Distanciados da realidade que haviam vivido até o momento do encontro com a deficiência, Ana e Antônio unem-se a essas alteridades, cada um à sua maneira, em uma dimensão hermenêutica que busca uma nova produção de sentidos. As personagens não podem escolher o encontro - a alteridade lhes foi apresentada sem que desejassem porém, a partir deste encontro, a reconfiguração de suas identidades será tarefa que terão de assumir, pois a postura hermenêutica de estabelecer novos sentidos será condição para suas existências.

\section{Referências}

ALONSO, Mariângela (2013). As grossas patas de um sensível elefante de circo: grotesco e comicidade na ficção de Clarice Lispector. Estudos Linguísticos, São Paulo, v. 42, n. 3, p. 1.319-1.332, set./dez.

ARISTOTLE (1982). Poetics. New York: Norton \& Company.

CASTORIADIS, Cornelius (1991). A instituição imaginária da sociedade. Rio de Janeiro: Paz e Terra.

CHEVALIER, Jean; CHEERBRANT, Alain (2015). Dicionário de Símbolos. 28. Ed. Rio de Janeiro: José Olympio.

DURAND, Gilbert (1988). A imaginação simbólica. São Paulo: Cultrix.

FRANCO-JÚNIOR, Arnaldo (2002). Da crítica ao mau gosto: “O jantar", de Clarice Lispector. Revista de Letras, São José do Rio Preto, v. 42, n. 1, p. 139-150.

LISPECTOR, Clarice (2009). "Amor". In: LISPECTOR, Clarice (2009). Laços de família. Rio de Janeiro: Rocco.

PLATÃO (2012). O banquete. São Paulo: Edipro.

RUIZ, Castor Bartolomé (2003). Os paradoxos do imaginário. São Leopoldo: Unisinos SANT'ANNA, Sérgio (1997). Um crime delicado. São Paulo: Companhia das Letras. 
Recebido em 29 de maio de 2017.

Aprovado em 16 de janeiro de 2018.

\section{resumo/abstract/resumen}

\section{A fratura da alteridade em "Amor", de Clarice Lispector, e Um crime delicado, de Sérgio Sant'Anna}

Valter Henrique de Castro Fritsch

O presente artigo busca discutir a condição da fratura humana em sua busca hermenêutica de dar sentido ao mundo que nos cerca através da compreensão da alteridade em duas obras literárias brasileiras: "Amor", de Clarice Lispector (1960); e Um crime delicado, de Sérgio Sant'Anna (1997). A partir da leitura e aproximação das duas obras e da jornada de seus protagonistas, busco analisar e compreender a fratura da alteridade a partir do contato das personagens Ana e Antônio Martins com pessoas com uma deficiência física - um homem cego e uma mulher manca, respectivamente - e como esse encontro com a alteridade da falta os modifica sobremaneira. Para tanto, utilizo o arcabouço teórico dos estudos do imaginário, na busca de uma hermenêutica da produção de sentidos através das imagens e da imaginação.

Palavras-chave: fratura, alteridade, deficiência física, estudos do imaginário, Clarice Lispector, Sérgio Sant'Anna.

\section{The fracture of otherness in Clarice Lispector's "Amor" and Sérgio Sant'Anna's Um crime delicado}

Valter Henrique de Castro Fritsch

This paper discusses the condition of human fragmentation in its hermeneutic quest to give meaning to the world that surrounds us through the understanding of otherness in two Brazilian literary works: "Amor" by Clarice Lispector (1960) and Um crime delicado by Sérgio Sant'Anna (1997). Reading the two works and their protagonists' journeys, I analyse the fracture of otherness that comes about through the contact that the characters Ana and Antônio Martins have with people with a physical disability - a blind man and a limp woman, respectively - and how this encounter with physical otherness changes the two characters. For this purpose, I use the theoretical framework of imagery studies, in the search for hermeneutics of the production of meanings through images and imagination.

Keywords: otherness, physical disability, imagery studies, Clarice Lispector, Sérgio Sant'Anna. 


\section{La fractura de la alteridad en "Amor" de Clarice Lispector y Um crime delicado de Sérgio Sant'Anna}

Valter Henrique de Castro Fritsch

El presente artículo busca discutir la condición de la fractura humana en su busca hermenéutica de dar sentido al mundo que nos rodea a través de la comprensión de la alteridad en dos obras literarias brasileñas: "Amor" de Clarice Lispector (1960) y Um crime delicado de Sérgio Sant'Anna (1997). A partir de la lectura y aproximación a las dos obras y de la jornada de sus protagonistas, busco analizar y comprender la fractura de la alteridad a partir del contacto de los personajes Ana y Antônio Martins con personas con una discapacidad física - un hombre ciego y una mujer manca, respectivamente - y como ese encuentro con la alteridad de la falta los modifica sobremanera. Para ello, utilizo el marco teórico de los estudios del imaginario, en la búsqueda de una hermenéutica de la producción de sentidos a través de las imágenes y de la imaginación.

Palabras clave: alteridad, deficiencia física, estudios del imaginario, Clarice Lispector, Sérgio Sant'Anna. 